\title{
Hacia una cultura del perdón. La misericordia y las bienaventuranzas como carta magna del creyente*
}

\author{
José Ignacio González Faus, \\ Facultad de Teología de Cataluña, \\ Centro de Reflexión Teológica, San Salvador.
}

No sé si es posible hablar del perdón de una manera objetiva, pero sospecho que no. Hay algunos campos en la vida (el perdón, el sexo, la belleza, cl amor, la poesía...) en los que el sujeto estŕ necesariamente tan autoimplicado, que nuestro lenguaje no puede manejarlos con la distancia con que maneja por ejemplo los números.

Una vez dicho esto, quisiera, en una primera parte, mostrar el valor hwmono del perdón: el perdón es un valor muy humano, pero que se trasciende a sí mismo y, por eso, es tan dificil de comprender, de justificar y de ejercitar. No es una recela, o una solución, pero es un ingrediente imprescindible. Una segunda parte nos dará la razón de lo anterior: el perdón es divino y, por eso, el valor humano del perdón tiene su fundamento en la revelación de Dios en Jesús. Pero desde el Dios de Jesús hay que volver siempre a los hombres: por eso en la tercera parte de mi charla intentare decir algo sobre una convivencia o "cultura" del perdón. Y para ello, tal como se me propuso, comentaré un poco esa "carta magna" del cristianismo que son las bienaventuranzas.

- El Instituco Dioceseno de Teología y Pastoral de Bilbao Grgenizb las jomedas «Paz y reconciliación en febrero de 1993. La finclided inmediate de estas jommins fue le de iluminar desde la teologia la sipuación de violencie del Pafs Vasco y su supereción En este nuimero publicanos les ponencins de Jose I. Conzflez Faus y de Jon Sobrino porque, mis alli de las sibueciones concretes del País Vasco y de El Salvador, ofrecen algunes reflexiones mis univertales sobse apecto de una cultura y wnespiritunlided en tiempos de violencie, fitiles inmbien pare tiempos de paz 
Y, presentando así el programa, pongamos manos a la obra

\section{El perdón como valor humano imprescindible}

Por las razones dichas al comienzo sobre la dificultad de hablar del perdón distanciadamente, decidí estructurar esta primera parte de mi charla como simple lectura comentada de un largo testimonio. Testimonio de un creyente de fuera y, por tanto, ni euskaldún ni espantol, laico (lo que puede liberar a sus palabras de la carga de moralina adherida a casi wodo lenguaje clerical), que posee la experiencia acumulada de su prolesión de historiador, y que, además, se ha distinguido en su trabajo por una lucha constante contra toda la pastoral del miedo y la culpabilización. Me refiero a Jean Delumeau, de quien voy a leer párrafos, en cursiva, de un largo texto tomado de su confesión de fe'.

\subsection{Definición del perdón}

El perdón es liberación, descarga, re-creación. Nos deja nuevos. Nunca se insistirá bastante en la necesidad del perdón. Devuelve la libertad y la alegria a los aplastados por el peso de la culpabilidad. Perdonar no significa ni olvido de la falta ni aquiesciencia anie ella. Es sólo un gesto de confianza ante otro ser humano: es un si a nuestro hermano.

Por muchas falsificaciones psicopatológicas que pueda tener el sentimiento de culpa, es evidente que existe y que es insoportable y frecuente. ¡Por eso es tan falsificable! Y por eso es tan normal que los hombres vivamos segregando justificaciones a diestro y siniestro. Y suelo decir que "el hombre es un ser que solo sabe hablar de sI mismo para justificarse". Y aunque la frase pueda tener su dosis de exageración, sirve para hacernos caer en la cuenta de hasla que punto los hombres somos seres necesitados de acogida $y$, sobre todo, de acogida frenle a la culpa.

Es también experiencia común que, si logramos comunicar nuestra culpabilidad, ello puede ser un alivio decisivo. Y ese alivio no radica simplemente en el hecho de haberse "descargado" sino en que, al decirlo, wno no se ha visto rechazado. $Y$ desde la fe anadimos que ese no ser rechazado es una palida señal de la situación fundamental del hombre ante Lo Definitivo que llamamos Dios: Dios nos acoge incondicionalmente, tal y como somos, y si pide nuestro cambio nunca es por esa satisfacción del autoritario que ve obedecidas sus órdenes, sino porque el cambio es lo mejor para nosotros misnos, porque él aspira a sacar de nosotros, la mejor versión posible de nosotros mismos. Desde Dios se comprende cómo el perdón no iene por qué ser complicidad ni indolencia, sino apuesta y confianza. Pero esto vendrá luego.

$Y$, desde esta experiencia personal, echemos una mirada a nuestro mundo. 


\subsection{Un mundo sin perdón}

Es posible que lo más opresor que existe en el mundo actual sea la ausencia de perdón. En otros tiempos -y a pesar de todos sus excesos traumatizantes-la pastoral invitaba al perdón que era una noción aceptada por el sentido común. Un condenado a muerte era ejeculado por la justicia ly a veces con refinamiento en los suplicios), pero, si se arrepentia, morla perdonado por Dios y por la Iglesia. $Y$, al menos desde la milad del s. XV en los palses católicos, las cofradias de la "buena muente" le asistian hasta el final. rezaban con él, lo comparaban al buen ladrón y le abrazaban los pies en señal de respeso. En nuestros dias, y fuera del espacio cristiano (que vambien ha encallecido su piel) ¿qué hay que sugiera perdonar?

Antaño el perdón era "una noción aceptada por el sentido común". Esto no quiere decir que la práctica se adecuase demasiado a esa aceptación. Pero sí nos pide que caigamos en la cuenta de que esa aceptación general ha desaparecido de nuestra cultura, quizá como consecuencia de que la noción de Dios también ha dejado de ser evidente.

El resultado de esa evidencia perdida es una especie de clrculo vicioso social: ¿quién pide hoy perdón? Casi nadie, a no ser como simple fórmula de cortesía ante inadvertencias de las que, precisamente, no somos culpables. $Y$ iquien perdona hoy? ¿No hemos introyectado más una especie de "evidencia previa" que nos sugiere que, ante el enemigo, la verdadera actitud es el ensaflamiento? La misma jerarqúa de la Iglesia (sobre todo la curia romana) zno parece demasiadas veces convencida de que ella está para refir, y no para anunciar y proclamar?

Y este rasgo de nuestra cultura, según Delumeau, está estrechamente vinculado a la vida política: ella lo engendra y se alimenta de él. Y ello, tanto en el esquema totalitario como en el de lucha de partidos. Oigamos a nuestro autor.

\section{La política: de locus carttatis (Mounier) a lugar del ensañamiento}

Bajo pretezto de ideologla se machaca hoy cada dla a los adversarios politi$\cos$ a quienes no se dirige ninguna palabra de esperanza, ninguna palabra que pueda confortar. Enemigos de derecha e izquierda se han mirado como irreconciliables, irrecuperables y carentes de todo derecho a la piedad. A escala planetaria la culpabilizacion, lejos de haber desaparecido, jambis ha sido tan fuerte desgraciadamente y jamnis ha producido tantas vicrimas. Pero nunca va acompañada de una palabra liberadora, de una mirada de comprensión. Antaño los cofrades de la buena muerte consideraban al ajusticiado como sólo un poco más culpable que ellos, que eran también pecadores como todos los hombres. Hoy, aguellos que torturan y fusilan están persuadidos de su buen hacer: quien no piensa como ellos no merece vivir.

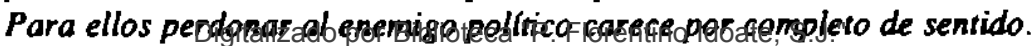


Quizás habría que comenzar preguntando a estas palabras si no tienen una rafz (o al menos un refuerzo) más profundo al que no citan, y que es nuestro sistema económico. Para mi, el sistema capitalista es el anverso de esa actitud cultural de ensafiamiento, el dinero hecho mercancía es el ídolo que no perdo$n a^{2}$, y la praxis de la competencia constante y absoluta es la que lleva al monopolio del pensamiento, fruto de que antes ha incubado la tentación de monopolio en el mercado.

Pero ahora podemos dejar esta consideración y ceñimos al texto que comentamos. Nuestros políticos se quejan de la desmovilización del ciudadano. Los ciudadanos podríamos responder que nos hemos cansado del discurso de los políicos porque no tienen nada propio que decimos que no sea "manchar al advercario so pretexı de ideología". Y actúan así porque éste les parece el camino válido para conseguir el poder, que es lo único que les interesa (aunque luego en el poder, nos han hecho experimentar que no se difcrencian mucho unos de otros: entre otras razones porque su margen de maniobra ante los poderes fácticos parece ser bastante estrecho).

Los ciudadanos debemos reconocer tambiên nuestra parte de culpa en ese pecado de los políticos: somos caldo de cultivo para ese pecado, porque es muy probable que un buen insulto les dé a ellos más votos nuestros que un buen argumento; y porque algo en nosotros también aspira a machacar al adversario ideológico.

El resultado es que, "a escala planetaria", no sólo no hay perdón (porque la necesidad de justifición del ser humano nos ha hecho creer que no lo necesitamos), sino algo peor. hemos pasado de menos perdón a más culpabilización mutua. Cosa paradójica dado que, cuando se desechó como inútil el perdón, se presuponia que era porque no existla la culpa. Pero ahora resulta que la que no existía era la culpa propia; la del otro es evidente que sí que existe. Y hoy más que nunca A veces, como el Segismundo de $L a$ vida es sueño, el otro nos resulta culpable sólo por el hecho de haber nacido.

Y una culpa sin perdón ha hecho que el castigo sea una categorla estructuradora de todas nuestras relaciones: desde el juego ("jotro gol!") hasta la relación personal ("para que aprenda"), la relación económica ("el máximo benelicio") y la política. Uno se acuerda de aquella frase del monólogo de Camus: "¿cómo quiere usted que tema yo el juicio de Dios, después de haber conocido el juicio de los hombres?". La mención de Dios me parece aquí oportuna porque se presupone que, si algo es, El es precisamente el que todo lo sabe. Y si su perdón no equivale a la ignorancia o a cerrar los ojos, tampoco puede ser eso el nuestro. Delumeau parece derivarlo más bien de una especie de "comunidad en la culpa" que evoca aquel verso diffcil de la Carta a los romanos: "todos son pecadores y necesitados de la gloria (que para Pablo es la misericordia) de Dios".

Digitalizado por Biblioteca "P. Florentino Idoate, S.J."

Universidad Centroamericana José Simeón Cañas 
En cualquier caso yo quiero comentar que no es lo mismo luchar como un perdonado que luchar como un inocente. Lo primero es cristianismo. Lo scgundo es simple fariscísmo.

$Y$ bien: todo esto puede sonar a tan tradicional que cause sorpresa. Y nuestro autor se ve obligado a preguntarse si es que ha cambiado de opinión:

¿Estoy quizás a punto de sucumbir a un pasotismo fácil, contrario a todos mis escritos anteriores que han pretendido desmirificar los tiempos de la cristiandad?

Su respuesta no nos habla de abandono, sino de complementaricdad. Oigámosle:

\subsection{Recuperar el perdón sin abandonar el compromiso}

Creo que no. Al revés: siempre he sostenido que aquélla, con sus luces y sus sombras, forma parte de nuestro patrimonio. Pues bien: me parece indudable que en la columna positiva del balance (y junso a orras realizaciones artissicas, culturales y espirituales) hay que colocar esta preciosa noción del perdón. Se me dirá que iodo eso es utopia (palabra bien poco actual). Responderé que nuestros días serían más llevaderos si el perdón tuviera más lugar en ellos.

No se trata pues de abandonar nuestras luchas, sino de colocar en ellas esa preciosa noción del perdón. La cual no convierte la relación humana en una utopía sin conflictos, pero pone el aceite que hace más soportable (y más cristiana) la conflictividad de la relación.

Si hablamos de aceite o de "volver más llevadero" ya se entiende que el perdón tampoco es vivido desde la superioridad del perdonavidas, sino desde la igualdad de lo fraterno. Esto es muy importante. En otro momento acuñé la expresión de "disenso misericordioso" (que tampoco quiere ser perdonavidas), para calificar la actitud que, en mi opinión, le pide hoy la responsabilidad eclesial a cualquier creyente prcocupado por la dolorosa situación involucionista de la Iglesia romana. Yo quizá debo pedir perdón por todo lo que mis disensos no hayan tenido de misericordiosos. Pero puedo también testificar que la misericordia no le quila nada al disenso. Lo hará más difícil, pero no menos auséntico.

Algo de esto es lo que me parece que quiere decir nuestro autor. $Y$ una vez establecida esta complementariedad (que siempre habrá de ser oscilante $\mathrm{cn}$ la casi imposible armonía de la complejidad humana), Delumeau vuelve a hacer aplicaciones concretas a niveles personales, nacionales e intemacionales. 


\section{a) Nivel personal}

En una epoca en que tantas parejas se desgarran y se separan. a pesar del evidente sufrimiento de tantos nirios y de los traumatismos psicológicos que se les produce, ino podrá el perdón recíproco aportar algo de alivio. comprensión, confortamiento, paz y alegrla? ¿No serla como un rayo de sol en nuestras lógrimas?

Vamos a dejar la alusión a los niños que, de todos modos, pone de relieve algo muy típico de nuestra cultura del "castigo": sólo el que tiene fuerza tiene en realidad derechos humanos. El débil, que ni tiene voz, ni puede castigar, es como si no tuviera derechos humanos. Vamos a cefliunos al innegable crecimiento de las separaciones que es un crecimiento del fracaso en las relaciones de pareja (reconocido asi por los mismos que se separan).

¿Por qué ha crecido? Puede haber casos de incompatibilidad de caracteres experimentalmente mostrada. Y hacer esta constatación es un innegable paso adelante. Pero no lodo ha sido eso.

Otras muchas veces ocurre que, cuando la alternativa y la diferencia se nos imponen como tales, y ya no producen esa gralificación inmensa de "dominar" o poseer lo desconocido, entonces nos desmontan, nos "sacan de nuestras casillas" (este giro castellano es sumamente expresivo), y reaccionamos ante ellas sintiéndonos agredidos y castigados. Ello hace degenerar la relación cada vez más, hasta que no haya más alternativa que el perdón o la guerra. Pero entonces, ya tarde, Iqué difícil resulta el perdón sobre todo si ha de ser mutuo o si alguien ha de dar arriesgadamente el primer paso! $Y$ sin embargo, si se hubiera hecho presente antes, cuando quizá todavía no era propiamente perdón, pero si reconocimiento, este "rayo de sol en las lágrimas" no las habría enjugado todas, pero al menos las habria relalivizado.

\section{b) Nivel nacional}

Y lo mismo vale dentro de cualquier pals. ¿Que cosa mós absurda que los adios y las culpabilizaciones reclprocas alimentadas entre nosotros por los dos mitos de la "derecha" y la "izquierda"? Me irrita siempre la repetición de esa vulgaridad comín a los pollticos de ambos campos: "No tengo lo no tenemos) ninguna lección que recibir de Fulano o de Mengano". "Al conirario! Todos renemos alguna lección que recibir de aquellos que no piensan como nosotros.

Ese "nada que aprender" de los que están al ouro lado de la trinchera es curiosamente una de las cosas que más daffan a la propia causa. Cuando ya ha pasado mucho tiempo, quizás alguna película como "La vaquilla" se propondrá mostrarnos que ambas parles podian aprender algo una de la otra. Pero mientras dura la batalla eso es inaceptable e incluso peligroso para la propia causa 
que, de este modo, se va convirtiendo en huida hacia adelante. Exactamente lo mismo ocurre a niveles mundiales:

\section{c) Nivel mundial}

Y por último: para la peligrosa tensión entre los supergrandes, para el problemo palestino, los conflictos raciales de Africa del Sur, los odios que dividen a los irlandeses y prenden fuego a Centroamérica, ¿qué otra solución existe más que el perdón y la comprensión del otro? Utopia, me repetirán. Está bien, pero, a pesar de todo, reflexionemos que no hay más que dos salidas posibles a las antinomias nacionales o internacionales que desgarran a nuestro mundo: o la guerra o el perdón. La solución del buen sentido es evidentemente la del perdón... ¿No nos alegramos de saber que el perdón vale más que la guerra?

La necesidad del perdón atraviesa así todos los ámbitos de la relación humana. No elimina su conllicuividad, al revés: se hace fan necesario porque la relación humana es conflictiva; y hoy que se encuentra tan degradada lo es todavia más. El perdón no es una utopía adonde evadirse, sino un ingrediente necesario para que el infiemo no sean los demás. Por eso el perdón no renuncia al cambio: en muchas ocasiones incluso lo provoca más ( $y$ desde luego mejor) que la gucra.

\subsection{Conclusión: sin perdón no hay humanidad}

Nuestro autor concluye con una anécdota que retomaremos después.

Un poesa cubano, profundamente cristiano, que ha pasado veintidós años en las cárceles de Fidel Castro. hizo hace poco delante de mí el elogio del perdón. Para él, perdonar es romper el engranage de la violencia, rechazar el combatir con las odiosas armas del adversario. seguir libre incluso cuando se está encadenando. $Y$ me dio, sobre este punto, un ejemplo cautivador: un día, él y sus compañeros de cautividad, corlaban caña de azúcar en un campo. supervisados por soldados. Estalló una tormenta. El rayo alcanzó a uno de los guardias por causa de su bayoneta. Los prisioneros fueron en su ayuda. le hicieron la respiración artificial... y lo devolvieron a la vida.

Puede que valga la pena destacar el dato ese de "profundamente cristiano" precisamente porque yo estoy intentando hablar aqui en plan humano. Pero vamos a concluir ya la lectura de este largo testimonio. El último párafo dc nuestro autor tiene cierto carácter de colofón y resumen:

Al contrario de esta conmovedora actitud, la falta tan frecuente de perdón hace que hoy dia "la obra maestra que se halla más en peligro es el hombre". Por eso los creyentes no debemos bajar los brazos ante la conspiración de silencio que rodea actualmente a la palabra y la realidad del perdón. Este consiuuye el único lazo posible de unión entre los hombres, y Universidad Centroamericana José Simeón Cañas 
enire los hombres y Dios. El es salud y es esperanza. El perdón es el arcoiris entre Dios y los hombres.

Otra vez, la metáfora del arcoiris no nos habla de solución utópica. sino de señal de esperanza. Pcro de una esperanza que nos obliga muy parlicularmente a los cristianos. A mí me gusta decir que la tarea del cristiano hoy no es propiamente salvar a Dios (como afirman a veces los eclesiásticos sin darse cuenta de que para esa tarea Dios no necesita de nosotros, pues El puede salvarse solo), sino salvar lo humano. Y aquí es donde Dios sí que necesita (o ha querido necesitar) de nosotros.

Precisamente por esa delensa de lo humano, son insuficientes en lo que llevamos dicho las aclitudes puramente individuales (por muy elogiables que sean): hace falta algo estruclural, es necesaria una cultura del perdón. Porque en las relaciones humanas el perdón es siempre una salida de dos direcciones: pasiva y activa. Hay que aprender a perdonar, pero también a ser perdonados. Comencemos por esto segundo.

El que nunca tiene nada de lo que ser perdonado, no puede relacionarse con nadie o sólo puede hacerlo como un falso dios: desde la sumisión o la rendición del otro, pero nunca desde el mutuo re-conocimiento. Antaño la práctica del sacramento de la penitencia inyectaba en nuestras vidas actitudes de autoexamen y de autoacusación. Al desaparecer esa práctica por sus formas caducas (y por la negativa vaticana a buscar (ormas nuevas) han desaparecido de nuestras vidas las actitudes de autoacusación y todos vivimos y hablamos acusando a los demás, sobre todo a partir del momento en que dejamos de mitificarlos.

Esta es la dirección que he llamado "pasiva". La acliva está mucho más clara: olorgar el perdón es un gesto personal de confianza cuando hay razones presentes para desconfiar. Es decir, dar un sí al hombre, más allá de tantos motivos para decirle NO. Es concretar en alguien como nosotros esa frase de Camus que todos aceptamos en abstracı, pero no sé si también en concreto: en los hombres hay más cosas dignas de admiración que de desprecio.

Me gustaría que el testimonio del historiador francés nos haya acompañado suficientemente en la exploración de esa terra ignota que es hoy el perdón. Todo lo anterior era el texto de un creyente y terminaba con el ejemplo de un hombre "profundamente cristiano". Ello nos lleva en una segunda parte a preguntar qué papel juega Dios en esa realidad del perdón que intentamos analizar ${ }^{3}$.

\section{Jesús de Nazaret: la fundamentación del perdón en Dios}

Quisiera mostrar que entre Dios y el perdón hay profunda vinculación en el nivel de los fundamentos, que no implica una necesaria conexión al nivel de los funcionamientos. Creo que algo de esto dejan ver unas palabras del ex Grapo Félix Novales, en una entrevista concedida desde la cárcel a yn diario de Barce-

Universidad Centroamericana José Simeón Cañas 
lona. Tras reconocer que "nccesito arrepentirme aun sabiendo que nunca dcjaré de ser un asesino", Félix continúa: "uno no se arrepiente ante los hombres sino ante Dios", confesión sorprendentc puesto que él acababa de reconocersc agnóstico. Por eso busca un camino de posibilidad para el perdón que a mí me parecc exacıo: "cuando se es agnóstico como yo, entonces debe arrepentirse ante la sociedad. Mi libro tienc la función de pedir públicamente perdón por mis pecados"'.

Es decir: el perdón entre los hombres es absolutamente autónomo en su funcionamiento (y esto basta para todos los hombres); pero ese mismo luncionamiento autónomo traduce una fundamentación en el perdón de Dios y en Dios como Perdón.

Cuando Jesús habla de Dios en los evangelios, nunca hace discursos ni suministra informaciones sobre El (que es lo que estúpidamente nos crecmos obligados a hacer los eclesiásticos). Simplemente habla de actitudes que provocan una experienicia: actitudes humanas para con El (llamarle Abba. "ya sabe lo que necesitan" etc.), actitudes de Dios para con los hombres (de los pobres es su reino etc.), o actitudes de los hombres entre nosotros (ha amado mucho, si a alguien se le perdona menos es señal de que ama menos, elc.).

La comunidad cristiana siguió, a partir de aqui, un interesante proceso de reflexión que intentaré resumir en tres pasos.

En primer lugar está el recuerdo aún vivo de Jesús: era un hombre que acogía a las personas. Luchaba contra las estructuras y las instituciones, pcro acogía a las personas. A todas (y si en algún momento se enfrenta con personas es siempre con colectivos, y con aquellos colectivos que son los responsables de las estructuras y las instituciones: los ricos y las autoridades). Esta conducta de Jesús fue leida (quizás ya por él mismo) como conducia de Dios: "tus pecados te son perdonados" quiere decir exactamente: si yo te acojo así, es porque Dios te acoge así.

En segundo lugar, desde aquí, la primitiva comunidad lee la resurrección de Jesús como la puesia en acio universal de esa actitud de Dios. Pueden comprobar en los sermones de los Hechos de los Apóstoles, lo vinculados que están anuncio de la resurrección de Jesús y anuncio del perdón para todos. Al resucitar a Jesús, Dios desautoriza al sistema humano que le condenó a muerte en nombre de Dios. Pero no lo hace destruyendo a quienes le condenaron, sino realizando hasta el máximo aquella suprema dignificación del hombre (o filiación divina) por la que Jesús luchaba.

Y por último, ese descubrimiento que hace la comunidad primitiva, unificando el recuerdo de Jesús y la resurrección de Jesús, se continúa después en esta enseñanza del Nuevo Testamento: "¿quién acusará a los elegidos de Dios?" (Ro 8, 33). Y la carla comenta que es Dios mismo el que nos accusa, pero lo que

Universidad Centroamericana José Simeón Cañas 
ocurre es que Dios "acusa" de otro modo, perdonando, acogiendo, convirtiendo la mucrte de Jesús en salvación nuestra. Esto desautoriza nuestros modos humanos, condenatorios, de acusar. Pero tampoco "pacta" en modo alguno con nuestro pecado, pues, por así decirlo, nos deja puestos en evidencia. Es claro para nosotros los cristianos que sólo porque Dios acusa de ese modo podemos nosotros decir: "yo me acuso". Cuando Juan repite machaconamente a lo largo de su evangelio que "el que cree no es juzgado", ello se debe a que quien cree en Dios como Perdón se juzga él a sí mismo al recibir ese perdón. A esta forma experiencial de creer en Dios como Perdón es a lo que Juan llama "conocer a Dios", $y$, a lo largo de su evangelio, la va contraponiendo a otras creencias y apelaciones a Dios que "no conocen a Dios" ( $c f$. Jn $8,54.55 ; 17,3$ 17,25), y que sólo sirven para arrogarse la autoridad de "matar a los hombres" (es decir: Ja forma suprema de negación del perdón) "creyendo hacer un servicio a Dios" (Jn 16,13). Es muy llamativo lo poco que sobre esto hemos reflexionado los cristianos.

Pues bien, este Dios así conocido es el Fundamento del perdón en su doble vertiente activa y pasiva a que antes aludí. Y es lástima que, luego, la historia de la penitencia, que debería actuar ese Fundamento, haya acabado por oscurecerlo demasiado. El perdón entra en la historia de la humanidad por el cristianismo; y los cristianos lo hemos hecho tan requetemal que hemos dado la impresion de que es la culpa lo que el cristianismo ha introducido en la historia humana.

En resumen: aunque no sea solución, sino ingrediente imprescindible, el perdón es una realidad profundamente humana. Es tan humano porque estó anclado en Dios mismo, y en la relación de Dios con el hombre.

Esta era la conclusión que persegulamos. Pero el perdón es, en algún sentido, medida de emergencia. Se actúa sobre todo en situaciones-límite o que van acercándose al límite. El ideal de la relación humana sería más bien que el perdón no haya sido necesario porque antes de él estaba y actuaba el re-conocimiento muluo. Y ese entomo que hace innecesario al perdón es lo que en el título de mi charla se expresa como "cultura de las bienaventuranzas". Diremos unas palabras sobre ella para terminar.

\section{De la cultura del castigo a la cultura de la dicha inesperada: las Bienaventuranzas}

Eso que llamamos la "cultura" humana tiene mucho que ver con la búsqueda y la experiencia de la dicha. En este sentido las bienaventuranzas evangélicas, en cuanto comienzan todas con un "dichosos...", presentan una especie de raíces, o de semillas, para una determinada culbura, para una visión del mundo y del hombre, la cual (como ahora mostrare) giraria en tomo a la justicia y la misericordia (bienaventuranzas cuarta y quinta - las dos centrales- de san Mateo). Y giran en torno a esos dos polos corno traducción humana del Dios Universidad Centroamericana José Simeón Cañas 
que es Perdón - lo que acabamos de ver- y que hace justicia precisamente "perdonando" y cambiando al hombre.

\subsection{Lucas y Mateo: situación y actitud}

Pero las bienaventuranzas plantean un problema ya clásico, debido a sus dos diversas versiones en Mateo y en Lucas. Se acusa a veces a Mateo de dar una versión "espiritualista" de lo que en Lucas tiene un luerte acento material. Lo cual, hablando precisamente de la cultura y de la dicha, tendría unas serias consecuencias reaccionarias (basta como ejemplo el paso de los "pobres" a los "pobres de espíritu").

Es fácil mostrar que el autor de esa falsa espiritualización de las bienaventuranzas no fue san Mateo, sino los ricos de nuestro tiempo. Digamos antes que, casi con seguridad, las palabras de Jesús están mejor reproducidas en la versión de Lucas que en la de Mateo. Pero esto no quita ningún interés a la versión mateana sino que, por el contrario, le da un interés mayor para lo que nosotros buscamos ahora que es una cultura de las bienaventuranzas.

¿Por qué? Retomo aquí una antigua formulación mía que decía que Mateo ha añadido a Lucas otras cuatro bienaventuranzas, que son bienaventuranzas de

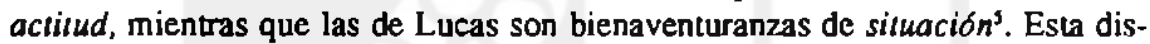
tinción me parece muy importante, pero debe ser prolongada: todas las bicnaventuranzas de Mateo, y no sólo las cuatro añadidas, son bienaventuranzas de actitud como ahora veremos. Mientras que las de Lucas (y muy probablementc las que pronunció Jesús) fueron bienaventuranzas de situación.

Ahora bien, la actitud es una determinada forma de reaccionar y de comportarse ante una determinada situación. Es como si san Mateo dijese: si Jesús llamó bienaventurados a quienes están así, ustedes tienen que pensar así. Son una manera de responder a Jesús y, en este sentido, Gustavo Gutiérrez acierta cuando califica a la versión mateana como bienaventuranzas "del discipulado"s. En este sentido se las puede llamar también "bienaventuranzas por el Espíritu", lo cual tiene un sentido diverso de la falsa espiritualización a que antes aludíamos.

Y, como he dicho, esta óptica actitudinal no afecta sólo a las cuatro bienaventuranzas que afiade Mateo (mansedumbre, limpieza de corazón, misericordia y pacificación), sino que colorea también su versión de las cuatro que tiene en común con Lucas: los pobres, los hambrientos, los que lloran y los perseguidos. Intentemos verlo.

a) Los pobres de espiritu no son los que tienen el bolsillo repleto y el corazón supuestamente "desprendido" de ese tesoro. Tal desprendimiento no existe, y Jesús era mucho más realista que mis amigos del Opus Dei cuando decía que donde está tu tesoro allí está también tu corazón. Son los pobres por el Esplritu, 
es decir: los que se han hecho voluntariamente pobres; cosa que sólo puede llevarse a cabo por la acción del Espínitu de Dios en uno?. Ante el clamor del hambre y de la miseria mundial uno reacciona empobreciéndose. Y este extraîo criterio del Espíritu Santo debe ser configurador de mentalidad y de cultura.

b) La bienaventuranza de los que lloran tampoco es idéntica en Mateo y Lucas a pesar del descuido de muchas traducciones. Mateo también ha dado aquí su pincelada aclitudinal a lo que en Lucas era descripción de una situación. Lucas dice: dichosos ustedes los que ahora lloran (en segunda persona y con el verbo klaiô). Mateo quila el ahora, habla en tercera persona (genéricamente por tanto) y cambia el verbo: dichosos los que estón afligidos (penthountes) según la tradición de Bover que es la que más me gusta". Están afligidos por el dolor del mundo (el hambre, el llanto, la miseria y la persecución). Se trata pues de una reacción ante la situación descrita por Lucas. Y esa reacción ("estar alligidos" y no precisamente estar coléricos) es la única manera de cambiar bien el mundo.

c) Así se comprende también la variante introducida por Mateo en su cuarta bienaventuranza: ahora no se trata simplemente de los que están en situación de hambre, sino de los que tienen hambre (y sed, añade Mateo) de justicia. El hambre de justicia es la reacción del Espíritu ante el hambre de este mundo: con lo cual se nos dice también que el hambre no es mera calamidad natural, sino injusticia (en perfecto paralelismo con el dato de que Jesús llamaba también injusıa a la riqueza9). Esa hambre de justicia debe ser también una actitud fontal, creadora de cultura.

d) Quizás ahora entenderemos el lío que arma Mateo con la octava bienaventuranza, que él parece repetir dos veces. Pero no es así: la primera vez es su octava bienaventuranza: "dichosos los perseguidos por su fidelidad" (en tercera persona). La segunda es como un resumen o balance de las ocho actitudes bienaventuradas y, por eso, ahora habla en segunda persona: dichosos serán ustedes cuando les maldigan y hablen mal de ustedes por $M I$. Esto que Mateo ha presentado como resumen es formulación más cercana a la cuarta bienaventuranza de Lucas: porque no sólo habla de persecución, sino de maledicencia, desprecio, etc. Y porque dice por Mi (Lucas dice "por el hijo del Hombre"). En cambio, la oclava bienaventuranza de Mateo sólo habla de persecución, y no dice "por Mí", sino "por causa de la justicia". La palabra (dikaiosynê) es la misma que en su cuarla bienaventuranza, y es ya sabido que en griego puede significar dos cosas: la justicia (antes hemos traducido hambre de justicia) y la fidelidad. La Nueva Biblia Española traduce ahora como fidelidad, y es probable que tenga razón, pues la fidelidad es la última actiud que debe acompañar a las siete actitudes anteriores ante el dolor humano. Pero da lo mismo si aceptamos la otra versión: que uno es perseguido por su (hambre de) justicia.

Estc es más o menos el sentido de la octava bienaventuranza. $Y$ ahora se comprende tambiéng por qué Maien cuando luego repite esta bienaventuranza de Universidad Centroamericana José Simeón Cañas 
la persecución como recapilulación de todas, cambia el motivo y dice "por Mi". Efectivamente: esas ocho actitudes son el despliegue de la actitud de Jesús, o del Esplrisu de Jesús, que traduce la actitud de Dios como Perdón.

\subsection{El texto de Mateo: centralidad de "justicia y misericordia"}

$\mathrm{Y}$ ahora que ya tenemos situadas como actitudinales las cuatro bienaventuranzas en que Mateo parece coincidir con Lucas, vamos a esudiar las ocho en bloque, anadiendo, por tanto, las cuatro lípicas de Mateo: misericordia, pureza de corazón, mansedumbre, pacificación.

Hay un esquema literario bastante aceptado que cree que las ocho bienaventuranzas se relacionan según un esquema "quiástico" o circular. La primera tiene que ver con la última (sólo de ambas se dice que "de ellos es el reino"), la dos con la siete (los mansos y los pacíficos ${ }^{10}$ ), la tercera con la sexta (sufrimiento y limpieza de corazón) y, como centrales, la cuarta y la quinta: hambre de justicia y misericordia. Este esquema nos visualiza un acercamiento bastante sencillo a esa "mentalidad" de las bienaventuranzas que es la cultura de la misericordia y de las actitudes derivadas de ella. Veámoslo:

\section{a) La cuarta y la quinta (hambre de justicia y misericordia)}

La bienaventuranza central es la misericordia. Y la misericordia no se contrapone a la justicia, sino que se realiza como hambre y sed de justicia. Aquí está oura vez la síntesis entre gracia y exigencia que nosotros tendemos a destruir: una misericordiosa sin hambre de justicia puede quedarse en mera sensiblería interesada. $Y$ un hambre de justicia que no brote de la misericordia se quedará en pelagianismo u orgullo prometeico.

\section{b) La tercera y la sexta (compasivos-limpios de corazón)}

Esa actitud central de la misericordia justiciera se despliega inmediatamente en la com-pasión (en el sentido etimológico de sufrir-con) a la que le corresponde una purificación de la mentalidad: la mente limpia (como los ojos limpios) son los únicos que pueden ver claro y bien. Para la antropología b乃blica el hombre no ve sólo con la razón, sino también con el corazón. Y éste, cuando no está absolutamente limpio, empafia la vista de la razón y le impide ver. Lo primero que no "ve" la mente sucia es a Dios, en el sentido joánico del "conocer" al que aludimos antes; $y$, por tanto, no le ve aunque afirme creer en el. $Y$ al no "ver" a Dios como Misericordia y Perdón, no hace caso de la palabra de Dios que le dice "quiero misericordia y no sacrificios" (palabra de Oseas que Mateo cita dos veces"), se monta as! un dios a su gusto, más interesado en el culı que en la misericordia, y se queda aś sin percibir la dimensión más profunda y verdadera de la realidad: la injusticia del dolor y la vocación del hombre a luchar contra esa injustictiato por Biblioteca "P. Florentino Idoate, S.J."

Universidad Centroamericana José Simeón Cañas 


\section{c) La segunda y la séptima (no violentos-pacificadores)}

Esta compasión cognoscitiva es activa, pero actúa de manera pacificadora y no violenta. También en "doble dirección". Por un lado, al luchar por la justicia trabaja en realidad por la paz, puesto que la verdadera paz es el fruto de la justicia. Pero, por el otro lado, la lucha por la justicia, como fruto de la misericordia, liende a ser una lucha pacificadora, no violenta (y ésta parece ser la mejor traducción de nuestra segunda bienaventuranza: dichosos los no violenlos).

\section{d) La primera y la octava (empobrecidos-perseguidos)}

Y este afán por la no violencia se traduce en que el luchador por la justicia prefiere empobrecerse a ser prepotente en su opción por la justicia (o en su misma pobreza). Aunque en este mundo empecalado ese empobrecimiento acarreará probablemente la persecución, si uno se mantiene en él.

\section{La misión "cultural" de las bienaventuranzas}

Esta es la actitud de respuesta del discipulado a la situación injusta de este mundo, en la que - según Lucas- Dios toma radicalmente partido en favor de los oprimidos, declarándolos por ello bienaventurados. La misericordia purifica el corazón para ver, y esto lleva a alligirse, a sentir hambre y sed de justicia y a privarse. Todo eso se intenta hacer de una manera no prepotente y creadora de paz. Pero, precisamente por eso, lleva a la persecución y a la fidelidad incluso en medio de ella Porque lo que no puede descontarse es la reacción contraria del mundo ante esta actitud.

$\mathrm{Y}$ ahora aterizamos ya en nuestro tema: esta actitud no es exclusivamente una postura individual, sino está llamada a "crear cultura", como se desprende de las tres observaciones que Mateo añade a continuación: a) que esa actitud es "luz y sal": está por tanto para iluminar y fecundar, no para quedarse escondida (cf. Mt 5, 13-15); b) que esta actitud lleva hasta Dios y entronca con su revelación antigua sin destruirla, sino cumpliéndola (vv 17-19); c) pero que esta consumación implica un cambio radical y una vuelı del revés, que se expresa en la frase final: la justicia del reino no es cono la de los "sabios y fariseos" (v. 20) que suele ser la justicia de este mundo. Con ello queda claro que en Mateo no se trata en modo alguno de una espiritualización de Lucas (lo cual sería hipocresía y justicia "de escribas y fariseos"), sino de una élica más radical. Sus bienaventuranzas son así la carta magna del cristiano. Mejor aún: la carta magna del reino.

Y esto plantea una última pregunta con la que debemos concluir. ¿puede tener alguna cabida esa carta magna en un mundo al que reconocemos como al antirreino y para el que (precisamente por eso) pedimos que "venga a nosotros Tu Reino"? 


\section{Conclusión}

Que tiene alguna vigencia es indudable, puesto que creemos también que este mundo malo está profundamente sazonado e iluminado por esa semilla del reino, sin que para ello sea indispensable ser creyente ni estar en la Iglesia, dado que el Espiritu de Dios ha sido derramado "sobre toda carne", y nosotros sabemos que el mismo Jesús confiesa a veces que "no encuentra en Israel tanta fe" como fuera La vida sugiere en ocasiones promesas de una armonia embriagadora; pero las más de las veces es desesperadamente conflictiva. Y su misma confliclividad la vuelve pecadora, y empecatada. La pregunta es pues cómo hacer real la cultura de la misericordia, cómo positivizarla en estructuras y mentalidades, cómo hacer que la sal sazone y la luz alumbre.

La respuesta a esa pregunta es de todos: no es de uno solo ni mía sólo. Yo sólo puedo aportar unas consideraciones que me resultan útiles, y con las que voy a concluir.

En primer lugar no hay que pensar en "cambios tolales e inmedialos de sisterna" por más que ésa sea una ingenuidad repetida tanto por cristianos (milenarismos antiguos, "tercera edad" de Joaquín de Fiore...), como por no cristianos (marxismos no tan antiguos). Jesús prefería imágenes como la del grano de mostaza. Y por eso no vale ni aquella mentalidad de los ańos 60 , a la que todo parecía posible, ni esta mentalidad de los 90 a la que nada le parece posible. La cultura de las bienaventuranzas sera siempre una contracultura o una cultura contracorriente, pero que aspira a fermentar la masa Lo que se nos pide a los cristianos es esa lectura de los (signos de los) tiempos, que descubre en ellos lo que Paulo Freire llamaba "el inédito viable". Debemos reconocer que, en estos momentos, la jerarquía romana, converida en profela de calamidades, no ayuda demasiado a esta tarea. Pero tampoco esto es decisivo, y ahf́ está Juan XXIII para relativizarlo.

En segundo lugar, dentro de este marco modesto y paciente, conviene recordar otro consejo de Jesús: el reino ya estí aquí entre nosotros. No hay que buscarlo en la luna. Y esto quiere decir que cuando trabajamos, por ejemplo, por la abolición total de la pena de muerte, cuando nos manifestamos contra el racismo, cuando hacemos objeción sincera de conciencia (u objeción liscal en lo que toca a lo militar), cuando nos proponemos resolver los conflictos sentándonos en torno a una mesa hablando, en lugar de agredimos y desautorizarnos, cuando queremos hacer nuestra (y práctica) la opción por los pobres, cuando terroristas y víctimas se dan la mano, cuando seguimos fieles a la causa en momentos en que eso "ya no se lleva" y se nos pone en la picota por ingenuos o anticuados. . , en todos estos y otros momentos estamos intentando construir esa cultura de las bienaventuranzas. Para lo cual es preciso saber además que nuestras actitudes estructurales económicas son lo más contrario a esa culura de la misericordia, ni siquiera a dejarse interpelax mínimamente pgr ella. Y la econo- 
mía lo condiciona todo. No se trata de que "Dios está contra la economía" (esa es una interesada tergiversación de lo que queremos decir, que pretende desautorizarlo desfigurándolo). Pero sí de que Dios está contra este sistema económico.

Pero, en tercer lugar, con lo anterior tampoco podemos damos por satisfechos. En los ejemplos anteriores puede filtrarse eso que Jesús caracterizaba como la justicia del reino. Pero se filtra también mucho pecado nuestro, siempre que no abordamos esas causas desde la cultura de la misericordia (y los cristianos desde el Dios que es Perdón), sino desde la moda, desde el protagonismo personal o colectivo, desde el afán de estar con los "progres" y no con los pobres, desde la necesidad de tener un enemigo y un "chivo expiatorio" contra el que poder descargar justificadamente nuestras agresividades en lugar de convertirlas, desde el sentimiento de superioridad, desde un eficacismo carente del sentido de la gratitud, o desde el deseo de tranquilizar nuestra conciencia para poder regresar luego a nuestra pereza... Los años sesenta a que acabo dc aludir, pueden ser un modelo a evitar de muchas de estas impurezas.

Finalmente, la necesidad de mantener los dos puntos anteriores quizá nos lleve a una distinción cualitativa de los tiempos (lo que el Nuevo Testamento suele llamar kairoi). La mente humana y nuestra ascendencia cartesiana soportan muy poco la dialéctica de la realidad, y por eso preferimos ir cambiando como decía el Eclesiastés: "hay un tiempo para esto y un tiempo para lo otro". Hay momentos en que es preciso recobrar la explicilación del Dios de la Misericordia, porque parece que los funcionamientos ya se nos obturan si no les limpiamos bien el Fundamento. Ha habido otros momentos en que percibimos con traquilidad que Dios no nos creó para que nos ocupáramos de El, sino para que nos ocupemos de todos nosotros, y que es ahi donde El nos espera y quiere que le encontremos. Llega algún momento en la vida en que lo que parecía estúpido y sólo facuible por razones creycntes (por ejemplo, perdonar, dar el primer paso) comienza a parecer necesario por meras razones humanas, aunque a la vez quizá parezca imposible: es el momento de la crisis a la que suelen llevamos muchos de nuestros pecados. El cristianismo debería saber estar en cada momento. Y, sobre todo en el último de los cilados, habría de estar mostrando que es posible perdonar, que es posible la misericordia, que es posible dar ese "primer paso" que nos es tan temido y nos parece tan irracional. Y, si no nos es totalmente posible, mostrando que es posible al menos caminar en esa dirección. $Y$ que, aunque no lleguemos a la meta querida, caminando por esa dirección estamos de cara a Dios. Y caminar en la dirección contraria lleva al desastre.

Estas son mis aportaciones bien sencillas. Cuando acabe este ciclo de charlas, les quedará a ustedes la tarea de imaginar otras. 


\section{Notas}

1. Ce que Je crois, Paris (1985) 98.101.

2. Marx, como quizá recordaremos, hablaba de "la bestia del Apocalipsis" que extermina a los que no llevan su sello, con alusión a Apocalipsis 13, 16-17.

3. Me atrevo a remitir, para la segunda parte, a la "Carta a mis hermanos de ETA", recogida en mi Elogio del melocotón de secano. Córdoba (1992) 103-107, sobre todo por los textos que alli se citan.

4. La Vanguardia 30 de septiembre de 1990, Revista p. 3.

5. Cf. Jesús de Nazarel y los ricos de su tiempo. Madrid (1982) 50.

6. Cf. El Dios de la vida, Salamanca (1992) 240. Por eso Gustavo las presenta atinadamente como meollo de csa "ética del reino" que se mueve en un imposible "a caballo" entre gracia y exigencia.

7. Que ésta era la lectura de toda la tradición cristiana pucde verse en algunos textos de mi antología Vicarios de Cristo. Los pobres en la espiritualidad y la teología cristianas, Madrid 1991.

8. O "dichosos los que sufren" según el Nuevo Testamento de Juan Mateos.

9. Cf. Le 16.9, y el comentario en Jesús de Nazaret y los ricos... 34.

10. Con todo, para defender esla correspondencia habría que aceptar el orden en que nosotros aprendimos las bienaventuranzas y que tiene menor apoyo de códigos. Hoy la crítica textual sucle leer en segundo lugar la bienaventuranza de los que sufren, y como tercera la de los "mansos". El esquema propuesto lo sigue Gustavo Gutiérrez op. cis. 224.

11. Matco 9,13 y 12,17. 